\title{
Approximate Solution of Non-Linear Reaction-Diffusion in A Thin Membrane: Taylor Series Method
}

\author{
${ }^{1}$ J. Visuvasam, ${ }^{2}$ A. Meena, ${ }^{3}$ K. Nirmala, ${ }^{4}$ L. Rajendran \\ ${ }^{1}$ Ramanujan Research Center in Mathematics, \\ Saraswathi Narayanan College, \\ Madurai -625022, India. \\ visuvasam135@gmail.com \\ ${ }^{2}$ Ramanujan Research Center in Mathematics, \\ Saraswathi Narayanan College, \\ Madurai -625022, India. \\ meensphd@gmail.com \\ ${ }^{3}$ Department of Mathematics, Kalasalingam Academy of Research and Education, Deemed to be University, \\ Srivilliputhur-626126, India \\ nirmalanikil@gmail.com \\ ${ }^{4}$ Department of Mathematics, \\ AMET, Deemed to be University, \\ Chennai- 603112, India. \\ Corresponding Author: \\ raj_sms@rediffmail.com
}

Article History: Received: 11 January 2021; Accepted: 27 February 2021; Published online: 5 April 2021

\begin{abstract}
- the nonlinear reaction-diffusion cycle in the thin membrane that describes the chemical reactions involving three species is studied. The model consists of the system of on nonlinear reaction-diffusion equations. The closed type of analytical expression of concentrations for the enzyme was developed by solving equations using the Taylor series formula. This results in the mixed Dirichlet and Neumann boundary conditions. Taylor series method similar to exponential function method. This technique provides approximate and simple solutions that are quick, easy to compute, and efficiently correct. These estimated findings are compared to the nuxmerical results. There is a good agreement with the simulation results.
\end{abstract}

Keywords-Mathematical modelling; Non-linear reaction-diffusion equation; Thin membrane; Taylor series method; Numerical Simulation.

\section{INTRODUCTION}

According to the reaction mechanism $2 A+B \rightarrow$ product, a diffusion-controlled chemical reaction between two species $\mathrm{A}$ and $\mathrm{B}$ is considered to be a product. The reaction path consists of a coupled pair of simple, irreversible and fast reaction mechanisms [4].

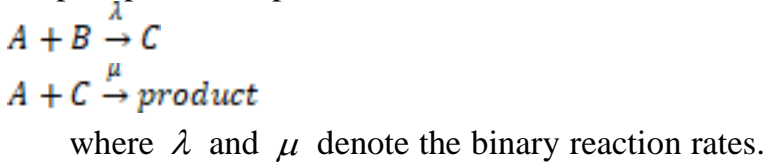

steady laminar flow of the third-grade fluid through a circular tube. Seidman et al. [2,3] and Kalacheve et al. 4] presented a detailed singular perturbation analysis of the steady-state problem. The corresponding non-steady state system of this problem was perceived by Haario Seidman [5] to describe the reactions in the film for the gas/liquid interface under the complex boundary conditions. Recently, Butuzov et al. [6, 7] have addressed many issues related to this problem using a variety of techniques. Rajendranet al. [8] and Ananthaswamy et al. [9] developed approximate analytical expressions for steady-state concentrations using the homotopy perturbation and homotopy analysis methods.

\section{Nomenclature}

\begin{tabular}{|l|l|}
\hline$u(\chi)$ & Dimensionless concentration of chemical species A \\
\hline$v(\chi)$ & Dimensionless concentration of chemical species B \\
\hline$w(\chi)$ & Dimensionless concentration of chemical species $\mathrm{C}$ \\
\hline$\chi$ & Dimensionless distance \\
\hline
\end{tabular}




\begin{tabular}{|l|l|}
\hline$\lambda$ & Dimensionless parameter \\
\hline$\alpha$ & Fixed concentration of the species \\
\hline$\beta$ & Fixed concentration of the species \\
\hline$\gamma$ & Fixed concentration of the species \\
\hline$q$ & Dimensionless reaction rate \\
\hline$m$ & Dimensionless Parameter \\
\hline$n$ & Dimensionless Parameter \\
\hline
\end{tabular}

II. MATHEMATICAL FORMULATION OF THE PROBLEM

The diffusion coefficients of three species are considered to have an equal diffusion coefficient which is equal to one. The non-linear diffusion reaction equation in the thin membrane is described by the following nondimensional format [4]:

$$
\begin{aligned}
& \frac{d^{2} u(\chi)}{d \chi^{2}}-\lambda u(\chi) v(\chi)-u(\chi) w(\chi)=0 \\
& \frac{d^{2} v(\chi)}{d \chi^{2}}-\lambda u(\chi) v(\chi)=0 \\
& \frac{d^{2} w(\chi)}{d \chi^{2}}-u(\chi) w(\chi)+\lambda u(\chi) v(\chi)=0
\end{aligned}
$$

where $u(\chi), v(\chi)$ and $w(\chi)$ denote the concentrations of the chemical species $\mathrm{A}, \mathrm{B}$ and $\mathrm{C}$ respectively. We assume that the specie $\mathrm{A}$ is supplied with a given fixed concentration $\alpha>0$ at $\chi=0$, and the specie $\mathrm{B}$ with $\beta>0$ at $\chi=1$. This results in the mixed Dirichlet and Neumann boundary conditions for the above Eqns. (3) -

(5) can be expressed as

$$
\begin{aligned}
& u=\alpha, \frac{d v}{d \chi}=0, w=\gamma \quad \text { at } \chi=0 \\
& \frac{d u}{d x}=0, \quad v=\beta, \frac{d w}{d x}=0 \quad \text { at } \chi=1
\end{aligned}
$$

The reaction rate $q$ is given by $q=\lambda u(\chi) v(\chi)$

III. CONCENTRATIONS IN THIN MEMBRANE USING TAYLOR'S SERIES METHOD

He $[15,16]$ suggests Taylor's series method to solve the Lane-Emden equation. This method also extended to all non-linear differential equation in fractional calculus [17, 18]. He recently proposed the exp-function method for solving the non-linear equations [18]. Visuvasam et al. [19] have derived the analytical expression for concentration profile and current using a hyperbolic function method and the Taylor series method. We can also obtain concentrations $u(\chi), v(\chi)$ and $w(\chi)$ using Taylor's series method (Appendix D) as follows:

$$
\begin{aligned}
& u(\chi)=\alpha+m \chi+\frac{\chi^{2}(\alpha \lambda n+\alpha \gamma)}{2} \\
& v(\chi)=n+\frac{\chi^{2} \alpha \lambda n}{2} \\
& w(\chi)=\gamma+b \chi+\frac{\chi^{2}(-\alpha \lambda n+\alpha \gamma)}{2}
\end{aligned}
$$

The analytical expression for reaction rate $q$ becomes,

$$
\begin{aligned}
q=\lambda u(\chi) v(\chi)=\lambda & \left(\alpha+m \chi+\frac{\chi^{2}(\alpha \lambda n+\alpha \gamma)}{2}\right) \\
& \left(n+\frac{\chi^{2} \alpha \lambda n}{2}\right)
\end{aligned}
$$

where

$$
\left.m=-\alpha(\lambda n+\gamma), n=\frac{2 \beta}{2+\alpha \lambda}, b=\alpha(\lambda n-\gamma)\right)
$$

A higher order in Taylors series provides a better approximation. Table-1 offers different estimated analytical representations of the concentrations and reaction rate available in the literature.

Table 1: Various approximate analytical expression of concentrations of $u(\chi), v(\chi)$ and $w(\chi)$.

The various approximate analytical solutions of concentration of $u(\chi), v(\chi)$ and $w(\chi)$ Homotopy Perturbation method [8], Homotopy Analysis Method [9] and our results are solved Taylor Series Method. 


\begin{tabular}{|c|c|c|}
\hline Ref. & $\begin{array}{l}\text { Approximate } \\
\text { analytical concentrations }\end{array}$ & Method \\
\hline [8] & $\begin{aligned} u(\chi)=\alpha+ & \frac{1}{2} \alpha \chi^{2} \lambda \beta+\frac{1}{2} \alpha \gamma \chi^{2}-\lambda \alpha \beta \chi-\alpha \gamma \chi \\
v(\chi)=\beta+ & \frac{1}{2} \alpha \chi^{2} \lambda \beta-\frac{1}{2} \lambda \alpha \beta \\
w(\chi)=\gamma- & \frac{1}{2} \alpha \chi^{2} \lambda \beta+\frac{1}{2} \alpha \gamma \chi^{2} \\
& +\lambda \alpha \beta \chi-\alpha \gamma \chi\end{aligned}$ & HPM \\
\hline [9] & $\begin{array}{l}u(\chi)=\alpha+h \alpha[\lambda \beta+\gamma]\left(\chi-\frac{\chi^{2}}{2}\right) \\
v(\chi)=\beta+\left(\frac{h \alpha \lambda \beta\left(1-\chi^{2}\right)}{2}\right) \\
w(\chi)=h \alpha(\gamma-\lambda \beta) \chi+\left(\frac{h \alpha(\lambda \beta-\alpha \gamma) \chi^{2}}{2}\right) \\
\text { where } \mathrm{h}=0.2\end{array}$ & HAM \\
\hline 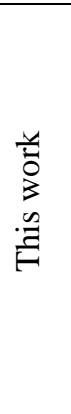 & $\begin{array}{l}u(\chi)=\alpha+m \chi+\frac{\chi^{2}(\alpha \lambda n+\alpha \gamma)}{2} \\
v(\chi)=n+\frac{\chi^{2} \alpha \lambda n}{2} \\
w(\chi)=\gamma+b \chi+\frac{\chi^{2}(-\alpha \lambda n+\alpha \gamma)}{2} \\
\text { where } \\
\left.m=-\alpha(\lambda n+\gamma), n=\frac{2 \beta}{2+\alpha \lambda}, b=\alpha(\lambda n-\gamma)\right)\end{array}$ & TSE \\
\hline
\end{tabular}

The analytical expression for reaction rate $q$ becomes,

$q=\lambda u(\chi) v(\chi)$

\section{NUMERICAL SIMULATION}

The nonlinear differential equation is solved numerically to investigate the accuracy of this analytical method. The detailed Matlab program for numerical simulation is provided in Appendix B. Figure 1 compares our empirical findings with the simulation results. In Tables 2 to 4 , our results are also compared with previous analytical results obtained using HPM and HAM. There is no significant difference in error percentage between the numerical and our analytical methods when the parameter $\lambda \leq 1$. The error percentage between the numerical other previous analytical methods is $8 \%$. Also, our method has the simplest form when compared to all other previous methods.

\section{DISCUSSION}

Equations (9) and (11) are the new closed and simple approximate analytical expressions of the concentrations of species $u(\chi), v(\chi)$ and $w(\chi)$ for all parameter values $\alpha, \beta, \gamma$ and $\lambda$. Fig.1a represent the normalized steady- state concentration species $u(\chi)$ for various values of the dimensionless parameter $\lambda$ and some fixed values other parameters. From this figure, it is evident that the values of the concentration of species A decrease when dimensionless parameter $\lambda$ increases at $\chi=1$. Figure $1 \mathrm{~b}$ shows concentration $v(\chi)$ for different dimensional parameter $\lambda$ and some fixed values for other parameters. From this figure, it is inferred that the value of the concentration will increase, when the dimensionless parameter $\lambda$ decreases at $\chi=0$ Fig. $1 \mathrm{c}$ illustrates the concentration $w(\chi)$ for distinct parameter values. From this figure, as the dimensionless parameter $\lambda$ decreases, the value of the concentration will increase.

Figs. (2a-2d). shows the dimensionless reaction rate $q$ using for various values of $\lambda$. Thus, it is concluded that there is a simultaneous increase in the values of the reaction rate as well as in $\lambda$ for the fixed value of $\alpha, \beta$ and $\gamma$. 

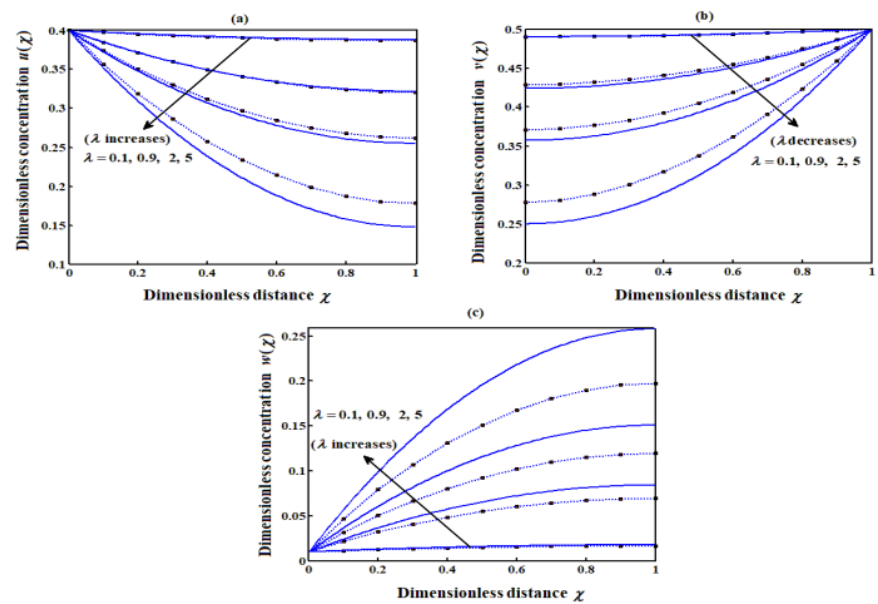

Fig.1. Normalized steady- state concentration $u(\chi), v(\chi)$ and $w(\chi)$ versus the dimensionless distance $\chi$ using eqns.(9-11) for various values of the dimensionless parameter $\lambda$ and fixed values for $\alpha=0.4, \beta=0.5$ and $\gamma=0.01$. Lines represent the analytical solution whereas the dotted lines for the numerical solution.
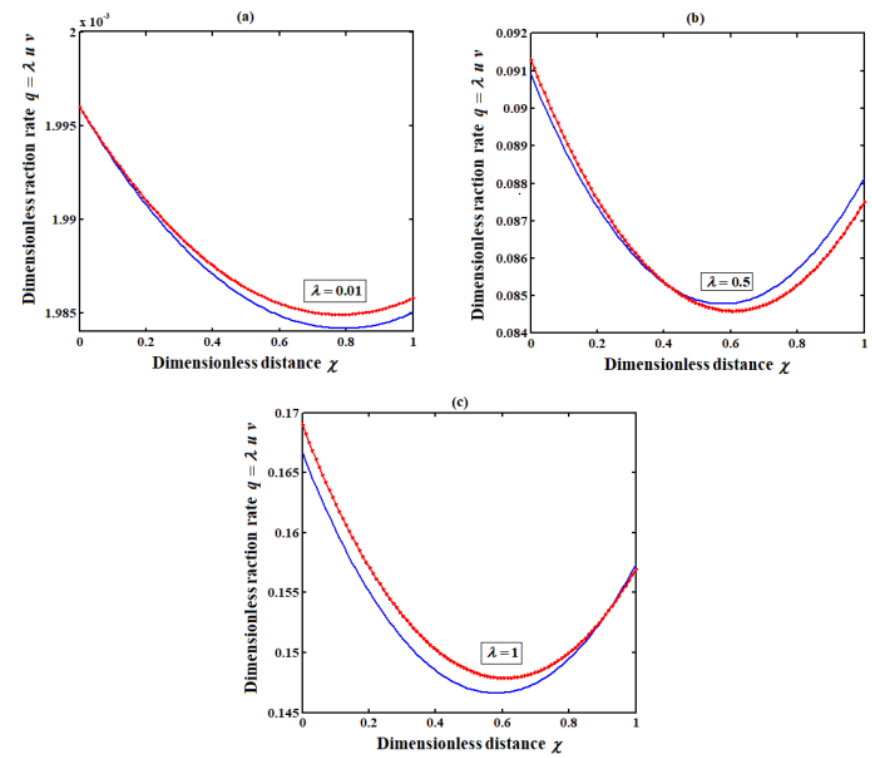

Fig. 2. Dimensionless reaction rate $q$ versus the dimensionless distance $\chi$ using (13) for the value of the dimensionless parameter $\lambda$ when $\alpha=0.4, \beta=0.5$ and $\gamma=0.01$. Lines represent the analytical solution whereas the dotted lines for the numerical solution.

\section{CONCLUSION}

In that paper a simple and efficient approach is introduced to solve the system of nonlinear reactiondiffusion equation in a thin membrane. Compared to other approaches the solution process is very simple and straightforward. Also, it can be extended to other boundary value problems in a thin membrane without any difficulty. Analytical expressions of the concentrations of species are derived by using the Taylor series method. Analytical and numerical simulation results are compared. Concentration and reaction rate, when the parameter $\lambda$ is less than one, give satisfactory agreement with simulation results.

\section{A. Appendix A: Approximate analytical solution of the equations (3-5) using Taylor series method}

Approximate analytical solution of the equations (3-5) using Taylors series method Taylor series method is accessible to all students and engineers; it might be the simplest analytical method [20-22]. More recently He [15] solved the convection-diffusion equation for E reaction arising in RDE using Taylors series method. The system of steady-state non-linear differential equations (3) - (5) in ECE reactions can be written as follows:

$u^{\prime \prime}(\chi)-\lambda u(\chi) v(\chi)-u(\chi) w(\chi)=0$ 


$$
\begin{aligned}
& v^{\prime \prime}(\chi)-\lambda u(\chi) v(\chi)=0 \\
& w^{\prime \prime}(\chi)-u(\chi) w(\chi)+\lambda u(\chi) v(\chi)=0
\end{aligned}
$$

The given boundary conditions for the above equations are

$u(0)=\alpha, v^{\prime}(0)=0, w(0)=\gamma$

$u^{\prime}(1)=0, v(1)=\beta, w^{\prime}(1)=0$

Now assume that

$u^{\prime}(0)=m$

The Eqn.(A.1) at $\chi=0$ we obtained

$u^{\prime \prime}(0)=\lambda u(0) v(0)+u(0) w(0)=0$

$u^{\prime \prime}(0)=\alpha(\lambda n+\gamma)$

Now assume that

$v(0)=n$

The Eqn.(A.2) at $\chi=0$ we find

$v^{\prime \prime}(0)=\lambda u(0) v(0)=0$

$v^{\prime \prime}(0)=\lambda \alpha n$

Now assume that

$w^{\prime}(0)=p$

when $\chi=0$ we obtained that the Eqn.(A.3) is

$w^{\prime \prime}(0)=u(0) w(0)-\lambda u(0) v(0)$

$w^{\prime \prime}(0)=\alpha(\gamma-\lambda n)$

The Taylor series solution of (A.1), (A.2) and (A.3) is

$$
\begin{aligned}
u(\chi) & =u(0)+u^{\prime}(0) \chi+\frac{1}{2 !} u^{\prime \prime}(0) \chi^{2} \\
& =\alpha+m \chi+\frac{\alpha(\lambda n-\gamma) \chi^{2}}{2} \\
v(\chi) & =v(0)+v^{\prime}(0) \chi+\frac{1}{2 !} v^{\prime \prime}(0) \chi^{2} \\
& =n+\frac{\lambda \alpha n \chi^{2}}{2} \\
w(\chi) & =w(0)+w^{\prime}(0) \chi+\frac{1}{2 !} w^{\prime \prime}(0) \chi^{2} \\
& =\gamma+p \quad \chi+\frac{\alpha(\gamma-\lambda n) \chi^{2}}{2}
\end{aligned}
$$

Now applying $\chi=1$ is series solution of $u(\chi), v(\chi)$ and $w(\chi)$ in Using equations (A.15) - (A.17) we get the constant $m, n$ and $p$.Differentiating the Eqn.(A.15) and using the boundary condition $u^{\prime}(1)=0$ we get constant

$m=-\alpha(\lambda n-\gamma) \chi$

The Eqn.(A.16) and using the boundary condition $v(1)=\beta$ we find constant

$$
n=\frac{\beta}{\left(1+\frac{\lambda \alpha}{2}\right)}
$$

Differentiating the Eqn.(A.17) and using the boundary condition $w^{\prime}(1)=0$ we obtained constant $p=-\alpha(\gamma-\lambda n)$

B. Appendix B: Numerical solution of nonlinear equations (3)-(5).

function sol $=\mathrm{ex} 6$

solinit=bvpinit(linspace $\left.(0,1),\left[\begin{array}{llllll}0 & 0 & 0 & 0 & 0 & 0\end{array}\right]\right)$;

sol=bvp5c(@ex6ode,@ex6bc,solinit);

end

function dydx=ex6ode $(x, y)$

$\mathrm{a}=0.4 ; \mathrm{b}=0.5 ; \mathrm{g}=0.01 ; \mathrm{l}=0.01$

$\mathrm{dydx}=[\mathrm{y}(2)$

$1 * \mathrm{y}(1) * \mathrm{y}(2)+\mathrm{y}(2) * \mathrm{y}(3)$

$\mathrm{y}(4)$ 


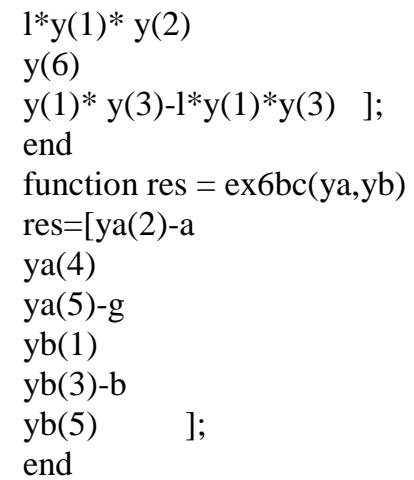

$\%$ Coding to run the programme

$\% 1$ st give this $\%$

solution=ex $6 ; \mathrm{x}=$ solution. $\mathrm{x} ; \mathrm{y}=$ solution. $\mathrm{y} ; \mathrm{y} 1=$ solution. $\mathrm{y}(1, \mathrm{)}) ; \mathrm{y} 2=$ solution. $\mathrm{y}(2,:) ; \mathrm{y} 3=$ solution. $\mathrm{y}(3,:) ; \mathrm{y} 4=\operatorname{solution} . \mathrm{y}(4$ ,:);y5=solution.y(5,:);y6=solution.y(6,:);

$\%$ 2nd give this \%plot(x,y1);

$\%$ To find $\mathrm{dw} / \mathrm{dx}$ at $\mathrm{x}=0$ run plot(x,y6); in MATLAB command window and find

$\%$ the value at $\mathrm{x}=0$ in that graph note the point for comparison

\section{ACKNOWLEDGMENT}

The Authors are also thankful to Shri J. Ramachandran, Chancellor, Col. Dr. G. Thiruvasagam, ViceChancellor, Academy of Maritime Education and Training (AMET), Deemed to be University, Chennai, for their constant encouragement. The authors are also grateful for their continuous encouragement to Dr.K.Sridharan, Chancellor, Dr.S.Shasi Anand, Vice- President, and Prof. Dr. R. Nagaraj, Vice-Chancellor, Kalasalingam Academy of Research and Education (KARE), Deemed to be University, Srivilliputhur-626126, India.

\section{REFERENCES}

1. Ariel P. D., "Homotopy Perturbation Method and Natural Convection Flow of a Third Grade Fluid Through Circular Tube," Nonlinear. Sci. Lett. A.1 , 43- 52., 2010.

2. Seidman T. I., and Kalachev L. V., "A One Dimensional Reaction /Diffusion System with a Fast Reaction," J. Math. Anal. Appl.209, pp. 392 - 414, 1997.

3. Seidman T. I., and Soane A. M., and Gobbert M. K. Numerical Exploration of a System of Reaction Diffusion with Internal and Transient Layers. Nonlinear Analysis: Real World Applications, vol. 6, pp. 914 - 934, 2005.

4. Kalachev L. V., and Seidman T. I., "Singular Perturbation Analysis of a Stationary Diffusion/Reaction System whose Solution Exhibits a Corner- Type Behavior in the Interior of the Domain". J. Math. Anal. Appl., vol.288, pp.722- 743, 2003.

5. Haario H., Seidman T. I., "Reaction and Diffusion at Gas / Liquid Interface II". SIAM J. Math. Anal., Vol.25,pp.1069-1084, 1994.

6. Butuzov V. F., Nefedov N. N., and Schneider K. R., "Singularly Perturbed Boundary Value Problems in case of Exchange of Stabilities," J. Math. Anal. Appl., Vol.229, pp.543- 562, 1999.

7. Butuzov V. F., Nefedov N. N., and Schneider K. R, "Singularly Perturbed Reaction- Diffusion System in case of Exchange of Stabilities," Natural Resource Modeling, vol.13, pp.247- 269, 2000.

8. L. Rajendran, V. Ananthaswamy, A. Eswari, "Analytical solution of system of non-linear reaction-diffusion equations in a thin membrane: Homotopy perturbation approach," Physical Chemistry: An Indian Journal, vol.5(2), pp. 97-102, 2010.

9. V. Ananthaswamy, A. Eswari, L. Rajendran, "Non- Linear Reaction- Diffusion Process in a Thin Membrane and Homotopy Analysis Method," International Journal of Automation and Control Engineering, vol.2 (1), 2013.

10. P.G. JansiRani , M. Kirthiga, Angela Molina, E. Laborda, L. Rajendran, "Analytical solution of the convection-diffusion equation for uniformly accessible rotating disk electrodes via the homotopy perturbation method,” J. Electroanal. Chem., vol. 799 , pp.175, 2017. 
11. J. Visuvasam, A. Molina, E. Laborda, L. Rajendran, "Mathematical models of the infinite porous rotating disk electrode," Int. J. Electrochem. Sci.,vol.13, pp.9999, 2018.

12. Liao S. J., "On the Homotopy Analysis Method for Non- Linear Problems". Appl. Math. Comput., vol. 147, pp.499- 513, 2004.

13. Liao S. J., "An Optimal Homotopy Analysis Approach for Strongly Non- Linear Differential Equations," Commun. Nonlinear Sci. Numer. Simulat., vol.15, pp.2003- 2016, 2010.

14. Liao S. J., "The Homotopy Analysis method in Non- Linear Differential Equations," Springer and Higher Education press, 2012.

15. J.-H. He, "A simple approach to one-dimensional convection-diffusion equation and its fractional modification for E reaction arising in rotating disk electrodes," Journal of Electroanalytical Chemistry, Vol. 854, $\quad$ pp. 113565, 2019.

16. Ji-Huan He, "A Fractal Variational Theory for One-dimensional Compressible Flow in a Microgravity Space," Fractals, Vol. 28(2), pp.2050024, 2020.

17. Chun-Hui He, Yue Shen, Fei-Yu Ji, Ji-Huan He, "Taylor Series Solution For Fractal Bratu-Type Equation Arising In Electrospinning Process,” Fractals, Vol. 28(1), Pp.2050011, 2020.

18. Ji-Huan He, Xu-Hong Wu, "Exp-function method for nonlinear wave equations,"Chaos, Solitons and Fractals., Vol.30, pp.700-708, 2006.

19. J. Visuvasam, A. Meena, L. Rajendran, "New analytical method for solving nonlinear equation in rotating disk electrodes for second-order ECE reactions," Journal of Electroanalytical Chemistry, Vol.869, pp.114106, 2020.

20. J. H. He, F.Y. Ji., "Taylor series solution for Lane-Emden equation," Journal of Mathematical Chemistry, vol.57, pp.1932-1934, 2019.

21. He, J.H., "The simplest approach to nonlinear oscillators," Results in Physics, vol. 15pp.102546, 2019.

22. He, J.H., "The simpler, the better: Analytical methods for nonlinear oscillators and fractional oscillators," Journal of Low Frequency Noise, Vibration and Active Control, vol.38, pp.1252-1260, 2019. 
${ }^{1} \mathrm{~J}$. Visuvasam, ${ }^{2}$ A. Meena, ${ }^{3} \mathrm{~K}$. Nirmala, ${ }^{4}$ L. Rajendran

Table. 2. Comparison between the analytical results and the simulation results for the concentrations of $u(\chi)$

\begin{tabular}{|c|c|c|c|c|c|c|c|c|c|c|c|c|c|c|c|c|c|c|c|c|c|}
\hline \multirow[b]{2}{*}{$\chi$} & \multicolumn{7}{|c|}{$\alpha=0.4, \beta=0.5, \gamma=0.01, \lambda=0.01$} & \multicolumn{7}{|c|}{$\alpha=0.4, \beta=0.5, \gamma=0.01, \lambda=0.5$} & \multicolumn{7}{|c|}{$\alpha=0.4, \beta=0.5, \gamma=0.01, \lambda=1$} \\
\hline & $\begin{array}{l}\text { Nume } \\
\text { rical }\end{array}$ & $\begin{array}{l}\text { Taylor } \\
\text { series } \\
\text { eqn. } \\
(17)\end{array}$ & $\begin{array}{l}\text { Previous } \\
\text { results } \\
\text { HPM } \\
\text { eqn.(9) }\end{array}$ & $\begin{array}{l}\text { Previous } \\
\text { results } \\
\text { HAM } \\
\text { eqn.(13) }\end{array}$ & $\begin{array}{l}\text { Taylor } \\
\text { series } \\
\text { error } \\
\text { eqn.(17) }\end{array}$ & $\begin{array}{l}\text { Previous } \\
\text { results } \\
\text { HPM } \\
\text { eqn.(9) }\end{array}$ & $\begin{array}{l}\text { Previous } \\
\text { results } \\
\text { HAM } \\
\text { eqn.(13) }\end{array}$ & $\begin{array}{l}\text { Nume } \\
\text { rical }\end{array}$ & $\begin{array}{l}\text { Taylor } \\
\text { series } \\
\text { eqn. } \\
(17)\end{array}$ & $\begin{array}{l}\text { Previous } \\
\text { results } \\
\text { HPM } \\
\text { eqn.(9) }\end{array}$ & $\begin{array}{l}\text { Previous } \\
\text { results } \\
\text { HAM } \\
\text { eqn.(13) }\end{array}$ & $\begin{array}{l}\text { Taylor } \\
\text { series } \\
\text { error } \\
\text { eqn.(17) }\end{array}$ & $\begin{array}{l}\text { Previous } \\
\text { results } \\
\text { HPM } \\
\text { eqn.(9) }\end{array}$ & $\begin{array}{l}\text { Previous } \\
\text { results } \\
\text { HAM } \\
\text { eqn.(13) }\end{array}$ & $\begin{array}{l}\text { Nume } \\
\text { rical }\end{array}$ & $\begin{array}{l}\text { Taylor } \\
\text { series } \\
\text { eqn. } \\
(17)\end{array}$ & $\begin{array}{l}\text { Previous } \\
\text { results } \\
\text { HPM } \\
\text { eqn.(9) }\end{array}$ & $\begin{array}{l}\text { Previous } \\
\text { results } \\
\text { HAM } \\
\text { eqn.(13) }\end{array}$ & $\begin{array}{l}\text { Taylor } \\
\text { series } \\
\text { error } \\
\text { eqn.(17) }\end{array}$ & $\begin{array}{l}\text { Previous } \\
\text { results } \\
\text { HPM } \\
\text { eqn.(9) }\end{array}$ & $\begin{array}{l}\text { Previous } \\
\text { results } \\
\text { HAM } \\
\text { eqn.(13) }\end{array}$ \\
\hline 0 & 0.4000 & 0.4000 & 0.4000 & 0.4000 & 0.0000 & 0.0000 & 0.0000 & 0.4000 & 0.4000 & 0.4000 & 0.4000 & 0.0000 & 0.0000 & 0.0000 & 0.4000 & 0.4000 & 0.4000 & 0.4000 & 0.0000 & 0.0000 & 0.0000 \\
\hline 0.2 & 0.3990 & 0.3989 & 0.3989 & 0.3998 & 0.0125 & 0.0127 & 0.2038 & 0.3822 & 0.3829 & 0.3813 & 0.3963 & 0.1906 & 0.2376 & 3.6809 & 0.3692 & 0.3693 & 0.3633 & 0.3855 & 0.0202 & 1.6049 & 4.4015 \\
\hline 0.4 & 0.3982 & 0.3981 & 0.3981 & 0.3996 & 0.0237 & 0.0241 & 0.3617 & 0.3682 & 0.3696 & 0.3667 & 0.3933 & 0.3789 & 0.4111 & 6.8191 & 0.3452 & 0.3454 & 0.3347 & 0.3741 & 0.0523 & 3.0376 & 8.3828 \\
\hline 0.6 & 0.3976 & 0.3975 & 0.3975 & 0.3995 & 0.0325 & 0.0329 & 0.4741 & 0.3582 & 0.3601 & 0.3563 & 0.3913 & 0.5463 & 0.5197 & 9.2363 & 0.3279 & 0.3283 & 0.3143 & 0.3661 & 0.1158 & 4.1533 & 11.6252 \\
\hline 0.8 & 0.3973 & 0.3971 & 0.3971 & 0.3994 & 0.0381 & 0.0386 & 0.5414 & 0.3521 & 0.3544 & 0.3501 & 0.3900 & 0.6682 & 0.5711 & 10.7714 & 0.3175 & 0.3181 & 0.3021 & 0.3612 & 0.1977 & 4.8424 & 13.7859 \\
\hline \multirow[t]{2}{*}{1} & 0.3972 & 0.3970 & 0.3970 & 0.3994 & 0.0400 & 0.0405 & 0.5638 & 0.3500 & 0.3525 & 0.3480 & 0.3896 & 0.7162 & 0.5824 & 11.3020 & 0.3139 & 0.3147 & 0.2980 & 0.3596 & 0.2458 & 5.0638 & 14.5606 \\
\hline & \multicolumn{4}{|c|}{ rror } & 0.0245 & 0.0248 & 0.3575 & \multicolumn{4}{|c|}{ Average error } & 0.4167 & 0.3870 & 6.9683 & \multicolumn{4}{|c|}{ Average error } & 0.1053 & 3.1170 & 8.7927 \\
\hline
\end{tabular}

Table.3. Comparison between the analytical results and the simulation results for the concentrations of $v(\chi)$

\begin{tabular}{|c|c|c|c|c|c|c|c|c|c|c|c|c|c|c|c|c|c|c|c|c|c|}
\hline \multirow[b]{2}{*}{$\chi$} & \multicolumn{7}{|c|}{$\alpha=0.4, \beta=0.5, \gamma=0.01, \lambda=0.01$} & \multicolumn{7}{|c|}{$\alpha=0.4, \beta=0.5, \gamma=0.01, \lambda=0.5$} & \multicolumn{7}{|c|}{$\alpha=0.4, \beta=0.5, \gamma=0.01, \lambda=1$} \\
\hline & $\begin{array}{l}\text { Nume } \\
\text { rical }\end{array}$ & $\begin{array}{l}\text { Taylor } \\
\text { series } \\
\text { eqn. } \\
(18)\end{array}$ & $\begin{array}{l}\text { Previous } \\
\text { results } \\
\text { HPM } \\
\text { eqn.(10) }\end{array}$ & $\begin{array}{l}\text { Previous } \\
\text { results } \\
\text { HAM } \\
\text { eqn.(14) }\end{array}$ & $\begin{array}{l}\text { Taylor } \\
\text { series } \\
\text { error } \\
\text { eqn.(18) }\end{array}$ & $\begin{array}{l}\text { Previous } \\
\text { results } \\
\text { HPM } \\
\text { eqn.(10) }\end{array}$ & $\begin{array}{l}\text { Previous } \\
\text { results } \\
\text { HAM } \\
\text { eqn.(14) }\end{array}$ & $\begin{array}{l}\text { Nume } \\
\text { rical }\end{array}$ & $\begin{array}{l}\text { Taylor } \\
\text { series } \\
\text { eqn. } \\
(18)\end{array}$ & $\begin{array}{l}\text { Previous } \\
\text { results } \\
\text { HPM } \\
\text { eqn.(10) }\end{array}$ & $\begin{array}{l}\text { Previous } \\
\text { results } \\
\text { HAM } \\
\text { eqn.(14) }\end{array}$ & $\begin{array}{l}\text { Taylor } \\
\text { series } \\
\text { error } \\
\text { eqn.(18) }\end{array}$ & $\begin{array}{l}\text { Previous } \\
\text { results } \\
\text { HPM } \\
\text { eqn.(10) }\end{array}$ & $\begin{array}{l}\text { Previous } \\
\text { results } \\
\text { HAM } \\
\text { eqn.(14) }\end{array}$ & $\begin{array}{l}\text { Nume } \\
\text { rical }\end{array}$ & $\begin{array}{l}\text { Taylor } \\
\text { series } \\
\text { eqn. } \\
(18)\end{array}$ & $\begin{array}{l}\text { Previous } \\
\text { results } \\
\text { HPM } \\
\text { eqn.(10) }\end{array}$ & $\begin{array}{l}\text { Previous } \\
\text { results } \\
\text { HAM } \\
\text { eqn.(14) }\end{array}$ & $\begin{array}{l}\text { Taylor } \\
\text { series } \\
\text { error } \\
\text { eqn.(18) }\end{array}$ & $\begin{array}{l}\text { Previous } \\
\text { results } \\
\text { HPM } \\
\text { eqn.(10) }\end{array}$ & $\begin{array}{l}\text { Previous } \\
\text { results } \\
\text { HAM } \\
\text { eqn.(14) }\end{array}$ \\
\hline 0 & 0.4990 & 0.4990 & 0.4990 & 0.4998 & 0.0004 & 0.0000 & 0.1603 & 0.4565 & 0.4545 & 0.4500 & 0.4900 & 0.4282 & 1.4239 & 7.3384 & 0.4224 & 0.4167 & 0.4000 & 0.4800 & 1.3573 & 5.3030 & 13.6364 \\
\hline 0.2 & 0.4990 & 0.4990 & 0.4990 & 0.4998 & 0.0004 & 0.0000 & 0.1539 & 0.4583 & 0.4564 & 0.4520 & 0.4904 & 0.4222 & 1.3744 & 7.0044 & 0.4257 & 0.4200 & 0.4040 & 0.4808 & 1.3370 & 5.0956 & 12.9456 \\
\hline 0.4 & 0.4992 & 0.4992 & 0.4992 & 0.4998 & 0.0005 & 0.0001 & 0.1347 & 0.4636 & 0.4618 & 0.4580 & 0.4916 & 0.3856 & 1.2092 & 6.0383 & 0.4353 & 0.4300 & 0.4160 & 0.4832 & 1.2144 & 4.4307 & 11.0074 \\
\hline 0.6 & 0.4994 & 0.4994 & 0.4994 & 0.4999 & 0.0006 & 0.0003 & 0.1028 & 0.4723 & 0.4709 & 0.4680 & 0.4936 & 0.3013 & 0.9172 & 4.5027 & 0.4509 & 0.4467 & 0.4360 & 0.4872 & 0.9401 & 3.3057 & 8.0493 \\
\hline 0.8 & 0.4996 & 0.4996 & 0.4996 & 0.4999 & 0.0008 & 0.0006 & 0.0583 & 0.4844 & 0.4836 & 0.4820 & 0.4964 & 0.1675 & 0.5053 & 2.4672 & 0.4725 & 0.4700 & 0.4640 & 0.4928 & 0.5194 & 1.7894 & 4.3065 \\
\hline \multirow[t]{2}{*}{1} & 0.5000 & 0.5000 & 0.5000 & 0.5000 & 0.0010 & 0.0010 & 0.0010 & 0.5000 & 0.5000 & 0.5000 & 0.5000 & 0.0040 & 0.0040 & 0.0040 & 0.5000 & 0.5000 & 0.5000 & 0.5000 & 0.0035 & 0.0035 & 0.0035 \\
\hline & \multicolumn{4}{|c|}{ Average error } & 0.0006 & 0.0004 & 0.1019 & \multicolumn{4}{|c|}{$\frac{1}{\text { Average error }}$} & 0.2848 & 0.9057 & 4.5592 & \multicolumn{4}{|c|}{ Average error } & 0.8953 & 3.3213 & 8.3248 \\
\hline
\end{tabular}

Table.4. Comparison between the analytical results and the simulation results for the concentrations of $w(\chi)$ 
Approximate Solution Of Non-Linear Reaction-Diffusion In A Thin Membrane: Taylor Series Method

\begin{tabular}{|c|c|c|c|c|c|c|c|c|c|c|c|c|c|c|c|c|c|c|c|c|c|}
\hline \multirow[b]{2}{*}{$\chi$} & \multicolumn{7}{|c|}{$\alpha=0.4, \beta=0.5, \gamma=0.01, \lambda=0.01$} & \multicolumn{7}{|c|}{$\alpha=0.4, \beta=0.5, \gamma=0.01, \lambda=0.5$} & \multicolumn{7}{|c|}{$\alpha=0.4, \beta=0.5, \gamma=0.01, \lambda=1$} \\
\hline & $\begin{array}{l}\mathrm{Nu} \\
\text { me } \\
\text { rical }\end{array}$ & $\begin{array}{l}\text { Tayl } \\
\text { or } \\
\text { serie } \\
\text { s } \\
\text { eqn. } \\
(19)\end{array}$ & $\begin{array}{l}\text { Previ } \\
\text { ous } \\
\text { result } \\
\text { s } \\
\text { HPM } \\
\text { eqn.( } \\
11)\end{array}$ & $\begin{array}{l}\text { Previ } \\
\text { ous } \\
\text { result } \\
\text { s } \\
\text { HAM } \\
\text { eqn.( } \\
15)\end{array}$ & $\begin{array}{l}\text { Tayl } \\
\text { or } \\
\text { serie } \\
\text { s } \\
\text { error } \\
\text { eqn.( } \\
19)\end{array}$ & $\begin{array}{l}\text { Previ } \\
\text { ous } \\
\text { result } \\
\text { s } \\
\text { HPM } \\
\text { eqn.( } \\
11)\end{array}$ & $\begin{array}{l}\text { Previo } \\
\text { us } \\
\text { results } \\
\text { HAM } \\
\text { eqn.(1 } \\
5 \text { ) }\end{array}$ & $\begin{array}{l}\mathrm{Nu} \\
\text { me } \\
\text { rical }\end{array}$ & $\begin{array}{l}\text { Tayl } \\
\text { or } \\
\text { serie } \\
\mathrm{s} \\
\text { eqn. } \\
(19)\end{array}$ & $\begin{array}{l}\text { Previo } \\
\text { us } \\
\text { results } \\
\text { HPM } \\
\text { eqn.(1 } \\
1)\end{array}$ & $\begin{array}{l}\text { Previ } \\
\text { ous } \\
\text { result } \\
\text { s } \\
\text { HAM } \\
\text { eqn.( } \\
15)\end{array}$ & $\begin{array}{l}\text { Taylo } \\
\text { r } \\
\text { series } \\
\text { error } \\
\text { eqn.( } \\
19)\end{array}$ & $\begin{array}{l}\text { Previ } \\
\text { ous } \\
\text { result } \\
\text { s } \\
\text { HPM } \\
\text { eqn.( } \\
11)\end{array}$ & $\begin{array}{l}\text { Previou } \\
\text { s } \\
\text { results } \\
\text { HAM } \\
\text { eqn.(15 } \\
\text { ) }\end{array}$ & $\begin{array}{l}\text { Nume } \\
\text { rical }\end{array}$ & $\begin{array}{l}\text { Tayl } \\
\text { or } \\
\text { serie } \\
\text { s } \\
\text { eqn. } \\
(19)\end{array}$ & $\begin{array}{l}\text { Previ } \\
\text { ous } \\
\text { result } \\
\text { s } \\
\text { HPM } \\
\text { eqn.( } \\
11)\end{array}$ & $\begin{array}{l}\text { Previ } \\
\text { ous } \\
\text { resul } \\
\text { ts } \\
\text { HA } \\
\text { M } \\
\text { eqn.( } \\
15)\end{array}$ & $\begin{array}{l}\text { Taylo } \\
\text { r } \\
\text { series } \\
\text { error } \\
\text { eqn.( } \\
19)\end{array}$ & $\begin{array}{l}\text { Previ } \\
\text { ous } \\
\text { result } \\
\text { s } \\
\text { HPM } \\
\text { eqn.( } \\
11)\end{array}$ & $\begin{array}{l}\text { Previou } \\
\mathrm{s} \\
\text { results } \\
\text { HAM } \\
\text { eqn.(15 } \\
\text { ) }\end{array}$ \\
\hline \multirow{2}{*}{0} & 0.01 & 0.01 & 0.010 & 0.000 & 0.00 & 0.000 & 100.0 & 0.01 & 0.01 & 0.010 & 0.000 & 0.000 & 0.000 & 100.00 & 0.010 & 0.01 & 0.010 & 0.00 & 0.000 & 0.000 & 100.00 \\
\hline & 00 & 00 & 0 & 0 & 00 & 0 & 000 & 00 & 00 & 0 & 0 & 0 & 0 & 00 & 0 & 00 & 0 & 00 & 0 & 0 & 00 \\
\hline 0. & 0.00 & 0.00 & 0.009 & 0.000 & 0.48 & 0.476 & 99.15 & 0.02 & 0.02 & 0.027 & 0.003 & 10.92 & 17.99 & 85.092 & 0.033 & 0.03 & 0.045 & 0.00 & 15.77 & 33.46 & 79.230 \\
\hline 2 & 97 & 96 & 6 & 1 & 40 & 6 & 76 & 31 & 56 & 3 & 4 & 04 & 84 & 7 & 9 & 93 & 3 & 70 & 99 & 53 & 4 \\
\hline 0. & 0.00 & 0.00 & 0.009 & 0.000 & 0.93 & 0.924 & 98.23 & 0.03 & 0.03 & 0.040 & 0.006 & 14.30 & 23.10 & 81.542 & 0.052 & 0.06 & 0.072 & 0.01 & 19.23 & 39.73 & 75.970 \\
\hline 4 & 94 & 94 & 4 & 2 & 84 & 9 & 87 & 31 & 78 & 7 & 1 & 60 & 04 & 2 & 0 & 21 & 7 & 25 & 54 & 13 & 5 \\
\hline 0 . & 0.00 & 0.00 & 0.009 & 0.000 & 1.30 & 1.289 & 97.25 & 0.04 & 0.04 & 0.050 & 0.008 & 15.95 & 25.48 & 80.106 & 0.064 & 0.07 & 0.092 & 0.01 & 20.78 & 42.37 & 74.742 \\
\hline 6 & 93 & 92 & 2 & 3 & 77 & 6 & 85 & 01 & 65 & 3 & 0 & 99 & 12 & 5 & 8 & 83 & 3 & 64 & 59 & 69 & 3 \\
\hline 0 . & 0.00 & 0.00 & 0.009 & 0.000 & 1.54 & 1.527 & 96.23 & 0.04 & 0.05 & 0.056 & 0.009 & 16.71 & 26.56 & 79.547 & 0.072 & 0.08 & 0.104 & 0.01 & 21.38 & 43.43 & 74.280 \\
\hline 8 & 92 & 90 & 0 & 3 & 85 & 7 & 54 & 43 & 17 & 1 & 1 & 74 & 55 & 3 & 6 & 81 & 1 & 87 & 80 & 84 & 3 \\
\hline \multirow{3}{*}{1} & 0.00 & 0.00 & 0.009 & 0.000 & 1.63 & 1.611 & 95.18 & 0.04 & 0.05 & 0.058 & 0.009 & 16.91 & 26.85 & 79.528 & 0.075 & 0.09 & 0.108 & 0.01 & 21.48 & 43.65 & 74.248 \\
\hline & 91 & 90 & 0 & 4 & 32 & 3 & 99 & 57 & 35 & 0 & 4 & 46 & 64 & 0 & 2 & 13 & 0 & 94 & 78 & 71 & 1 \\
\hline & & Aver & err & & $\begin{array}{r}0.98 \\
53\end{array}$ & $\begin{array}{r}0.971 \\
7\end{array}$ & $\begin{array}{r}97.68 \\
00\end{array}$ & \multicolumn{4}{|c|}{ Average error } & $\begin{array}{r}12.46 \\
97\end{array}$ & $\begin{array}{r}20.00 \\
03\end{array}$ & $\begin{array}{r}84.302 \\
8\end{array}$ & \multicolumn{4}{|c|}{ Average error } & $\begin{array}{r}16.44 \\
62\end{array}$ & $\begin{array}{r}33.77 \\
82\end{array}$ & $\begin{array}{r}79.745 \\
3\end{array}$ \\
\hline
\end{tabular}

